\title{
JÓVENES EN CUARENTENA: LA INVESTIGACIÓN SITUADA COMO MODO DE INTERVENCIÓN
}

\author{
MARIANA PATRICIA ACEVEDO ${ }^{1}$
}

\begin{abstract}
RESUMEN
Este artículo recopila preocupaciones, artículos y textos producidos en mi trayectoria de 35 años de investigadora y docente, cuyo eje central lo constituyen las reflexiones teórico-metodológicas y políticas en torno a y desde la investigación social en el campo de las juventudes, siguiendo a la investigación situada como forma de intervención social. Coloco especial énfasis en el proyecto de investigación que actualmente dirijo y desde el cual indagamos estrategias y circuitos de acceso que los jóvenes de sectores populares despliegan en contextos y tiempos de restricciones en torno a educación, trabajo y participación.
\end{abstract}

PALABRAS CLAVE: JUVENTUD, PANDEMIA, INVESTIGACIÓN SITUADA.

\footnotetext{
${ }^{1}$ Mariana Patricia, magíster en Ciencias Sociales. Docente - de grado y posgrado - e investigadora de la Facultad de Ciencias Sociales Universidad Nacional de Córdoba, Argentina. Dirige proyectos, tesis de grado y posgrado, publica artículos y libros en torno a Juventudes. Integrante del equipo Entre-generaciones, Colectivo de investigación y acción con jóvenes. Correo electrónico: pacevedo@unc.edu.ar
} 


\title{
JOVENS EM QUARENTENA: A PESQUISA SITUADA COMO FORMA DE INTERVENÇÃO
}

\begin{abstract}
RESUMO
Este artigo reúne as preocupações, artigos e textos produzidos durante minha trajetória de 35 anos como pesquisadora e professora, cujo eixo central é constituído pelas reflexões teóricasmetodológicas e políticas sobre e a partir da pesquisa social no campo das juventudes, seguindo a pesquisa situada como forma de intervenção social. Dou especial ênfase ao projeto de pesquisa que atualmente guio e a partir do qual indagamos estratégias e circuitos de acesso que os jovens de setores populares implementam em contextos e tempos de restrições em torno da educação, trabalho e participação.
\end{abstract}

PALAVRAS-CHAVE: JUVENTUDE, PANDEMIA, PESQUISA SITUADA.

\section{YOUTH IN QUARANTINE: SITUATED RESEARCH AS A FORM OF INTERVENTION}

\begin{abstract}
This article compiles the concerns, articles, and texts I have worked on throughout my 35-year career as a researcher and professor, centered on the theoretical, methodological, and political reflections about and from social research on youths, following the situated research as a form of social intervention. I emphasize on the research project I am currently running from which we inquire into strategies and access circuits displayed by working-class youngsters within contexts and times of restriction concerning education, work, and participation.
\end{abstract}

KEYWORDS: YOUTH, PANDEMIC, SITUATED RESEARCH. 


\section{INTRODUCCIÓN}

Este artículo es una versión revisada de diversas exposiciones (clases y conversatorios virtuales) que por primera vez —en mis más de 35 años de docencia universitaria- dicté frente una pantalla. Mis interlocutores, a quienes les hablé a través de una pantalla de computadora, fueron colegas y estudiantes de la Facultad de Ciencias Sociales de la Universidad Nacional de Córdoba, y otras Facultades y carreras de Ciencias Sociales del país.

Se sitúa en una línea de preocupaciones y textos que, de manera más o menos sistemática (en ocasiones de modo individual, pero siempre recogiendo procesos colectivos), vengo produciendo, cuyo eje principal lo constituyen las reflexiones teórico-metodológicas y políticas en torno a y desde la investigación social en campo de las juventudes.

Mis intervenciones se desarrollaron en el ciclo «Diálogos desde el Trabajo Social» ${ }^{2}$, una iniciativa impulsada por la carrera Licenciatura en Trabajo Social, en particular en el marco del Seminario de Diseño de Estrategias de Intervención que se dicta en el último año de cursado de dicha carrera. Agradezco a mis colegas Sabrina Bermúdez y Natalia Becerra por invitarme e impulsarme a ordenar y producir ideas en torno a un oficio que desarrollo hace años: la investigación social. A lo largo de mi carrera, he intentado combinar la gestión universitaria, la extensión, la docencia y la investigación, con particular énfasis en juventudes. Considero que estas son funciones de la Universidad Pública Argentina. Mi participación como directora de proyectos colectivos, tesis de grado y posgrado en temáticas de juventudes, y como coordinadora y docente de cursos y seminarios, constituyen espacios en los cuales poner en común conocimientos y experiencias, y recuperar saberes otres (y de otres).

\footnotetext{
${ }^{2}$ El ciclo completo de charlas está disponible en YouTube (shorturl.at/tzJQ5).
} 
En general, los temas propuestos por las colegas que me convocaron y sobre los que versaron mis exposiciones fueron: la relación entre investigación e intervención, y las tensiones y decisiones en el proceso de investigación. He tomado como referencia ambas exposiciones para construir el presente artículo, una acción intelectual que me apasiona y que desde hace largos años se nutre y nutre mi trabajo con jóvenes de sectores populares. De modo que la experiencia desarrollada (y aún en desarrollo) en contexto de pandemia por el equipo que dirijo se torna la referencia empírica desde y sobre la cual esbozo las ideas y contribuciones en torno a la investigación situada.

Voy a intentar mantener el tono coloquial, en tanto adopto la idea de Wright Mills (1999: 228) en torno a que «toda manera de escribir que no es imaginable como habla humana es una mala manera de escribir». Además, en el reconocimiento de procesos de producción colectivos y aportes de colegas, elijo escribir en primera persona del singular, por cuanto considero que la escritura en voz activa otorga carnadura a las ideas que exponemos y nos hace responsables de ello.

Dado que la producción y exposición de un artículo — a mi criterio- lejos está de una novela de misterio, el camino elegido es comenzar y concluir el artículo con la misma idea fuerza: investigación e intervención no solo se relacionan y retroalimentan, sino que además, desde la perspectiva de la investigación situada, puede concebirse a la misma como un modo de intervención. Tomo como referencia (teórica, política y empírica) la experiencia de investigación desarrollada por el equipo que dirijo: Jóvenes en cuarentena ${ }^{3}$.

\footnotetext{
${ }^{3}$ Jóvenes en cuarentena, una investigación situada sobre sus vivencias y experiencias (2020) es el título de la investigación realizada por el equipo Entre Generaciones, un colectivo de docentes, estudiantes, graduades y personas abocadas a la investigación y a la colaboración en la Facultad de Ciencias Sociales de la UNC, que trabaja en equipo desde el 2008.
} 
Enuncio las ideas fuerza desde las cuales recupero y produzco argumentos que permiten poner en diálogo una experiencia de investigación situada — Jóvenes en cuarentena- con diversos aportes de las ciencias sociales.

2. SER JOVEN EN LOS 80. TODES HABLAMOS, CONSTRUIMOS Y SOMOS CONSTRUIDES DESDE ALGÚN LUGAR. LOS APORTES DE LA TEORÍA DEL Punto de Vista Feminista (Nancy Hartsock, Evelyn Fox KELLER Y SANDRA HARDING) Y LA IDEA DE EL DOMICILIO DE LA inVESTIGACIÓN, PROPUESTO POR ALEJANDRO HABER

Voy a explicitar desde dónde hablo y para ello es necesario reconocer las diversas experiencias que me han constituido, parafraseando y tomando el título de la tesis de doctorado de la colega, Susana Garcia Salord ${ }^{4}$ : ¿Cómo llegué a ser quién soy? Se conjugan diversas posiciones que no son fortuitas, sino resultado de caminos, búsquedas y bifurcaciones.

Crecí y me formé en un pueblo del interior y soy la primera generación universitaria en mi familia. Me reconozco como producto de la educación pública argentina, desde el ciclo inicial a mis estudios de posgrado. Soy licenciada en Trabajo Social, magíster en Ciencias Sociales, docente e investigadora de la Facultad de Ciencias Sociales, podría decir también que soy funcionaria pública, ya que he combinado docencia e investigación con gestión universitaria. Me reconozco educadora popular y militante por la universidad pública, y los derechos humanos y sociales. Desde mis épocas de estudiante, cuando era una joven recién

\footnotetext{
${ }^{4}$ Investigadora del Instituto de Investigaciones en Matemáticas Aplicadas y en Sistemas, profesora de la Facultad de Ciencias Políticas y Sociales y miembro del Seminario de Educación Superior. Universidad Nacional Autónoma de México, DF. CP 04510. Correo electrónico: salord@unam.mx
} 
llegada de un pueblo del interior —allá por la recuperación democrática ${ }^{5}$ en Argentina-, trabajo con jóvenes ${ }^{6}$. Podría afirmar que desde que yo era joven, investigo, milito y trabajo con jóvenes. Devine feminista tardía por contacto con queridísimas colegas, amigas, militantes, y por mi hija y sus amigas. Siempre fui latinoamericanista y decolonial, pero no hace tanto pude ponerles palabras a mis pensamientos y acciones en tal sentido.

Si tuviera que identificar qué fue primero... ¿La educación popular, la investigación/acción o la formación de grado en trabajo social? ¿Las búsquedas de respuestas a la condición juvenil de los 80? ¿Las propias prácticas militantes y educativas como respuestas? Sin duda encontraría que — como en una espiral — todas y cada una de ellas se entrelazan, potencian, hacen parte de mí y de lo que hoy les comparto. Me auxilia la noción de generación ${ }^{7}$ para afirmar que gran parte de quienes fuimos jóvenes en los 80 en Argentina y formamos parte de la universidad de la «vuelta a la democracia», combinamos prácticas de investigación, educación popular, y acción social y política.

${ }^{5}$ El 30 de octubre de 1983, Raúl Alfonsín fue elegido presidente tras siete años y meses de dictadura militar. Esa jornada marcó un antes y un después para la historia argentina y su sistema político (en muchos sentidos). Se denomina período de la recuperación democrática al que va entre 1982 y 1985, aproximadamente.

${ }^{6}$ En 1982, junto a un puñado de jóvenes provenientes de diversas experiencias de militancia y trabajo con los sectores populares (parroquiales, desde los derechos humanos, la educación popular), nos nucleamos en una organización popular - SEAP - y desde la misma potenciamos e impulsamos trabajos territoriales en barrios populares y villas de la ciudad de Córdoba. La persistencia en el trabajo con jóvenes de sectores populares reconoce estos orígenes.

${ }^{7} \mathrm{La}$ aparición de nuevos individuos es un proceso biológico inevitable para la mantención de una especie, pero su constatación no explica por sí sola el significado social de las generaciones en tanto realidad, como define Mannheim a este fenómeno. En su esquema analítico, junto con haber nacido en períodos cercanos, el primer requisito para que puedan aparecer formas de ver, sentir y vivir la vida común a un conjunto de individuos es que compartan una misma situación de generación, que es el punto donde se unen el tiempo histórico y las condiciones sociales e históricas de existencia. Con la idea de situación de generación, Mannheim entrega al análisis una mayor precisión conceptual que le permite salvar el problema que supone poner en equivalencia la coetaneidad con la identidad subjetiva. El asunto hay que llevarlo al plano de las condiciones sociales y culturales en que viven los sujetos, pues son estas las que en definitiva determinan los modos de experiencia y conciencia posibles (Mannheim, 1993: 62). 
Y todo esto, ¿para qué? Para decir que todes somos seres situados e intervenidos por la familia, los amigos, las instituciones, por el tiempo y el espacio en el que vivimos y convivimos. $\mathrm{Y}$ es desde estos lugares que conocemos, miramos y actuamos en el mundo.

Harding (1996) afirma que es posible situarse en el proceso de investigación y hacerlo desde una autobiografía, es decir, desde una biografía del investigador. El concepto central de la epistemología feminista, de la cual Sandra Harding y Donna Haraway son algunas de sus exponentes, es que la persona que conoce está situada y por lo tanto el conocimiento es situado, es decir, refleja las perspectivas particulares de la persona que genera conocimiento, mostrando cómo es que el género sitúa a las personas que conocen. Desde la Teoría del Punto de Vista Feminista, Nancy Hartsock, Evelyn Fox Keller y Sandra Harding sostienen que el mundo se representa desde una perspectiva particular situada socialmente, que se basa en una posición epistémica privilegiada. Cuestiona las suposiciones fundamentales del método científico, sus corolarios de objetividad y neutralidad, así como sus implicaciones, y cuestiona los métodos que ponen distancia entre quien conoce y lo que se conoce, destacando el conocimiento situado basado en la experiencia de las mujeres que les permite un punto de vista del mundo distinto. Esta teoría propone que no hay una localización desde la cual se pueda desarrollar el conocimiento libre de valores o prejuicios, pero que algunas posiciones son mejores que otras y que el agente epistémico ideal no es un sujeto incondicionado, sino un sujeto condicionado por experiencias sociales.

Alejandro Haber (2011), autor al que llegué casi de manera fortuita y a quien leo con mucho interés, refiriéndose a la importancia de situarse en la investigación, acuña la idea de domicilio de la investigación y nos invita a preguntarnos: ¿de qué (no) material estamos (no)hechos?, ¿cuáles son las huellas que me constituyen y que me sitúan en este domicilio?, ¿de qué maneras me ha instrumentalizado (disciplinado) mi instrumento (disciplina)? Dirá este autor que es posible hablar de domicilio como trinchera, para fundamentar que en algún lugar vive nuestra escritura y nuestra investigación. Muchas veces ese sitio está estipulado 
por el disciplinamiento, por las reglas que rigen nuestras relaciones sociales como si fueran relaciones de conocimiento. Esto nos hace ignorar el sitio del propio domicilio. No es motivo de este diálogo, pero la noción de domicilio de la investigación me resulta una idea interesante y potente para seguir trabajando para comprender por qué algunes investigamos determinadas cuestiones y no otras; y qué hacemos con eso que investigamos, desde qué lugares o no lugares lo hacemos y qué estrategias utilizamos para provocar el conocimiento y hacerlos circular.

Dice un artículo de mi autoría:

En un sentido amplio, ninguna investigación tiene un comienzo concreto; por el contrario, existen una serie de circunstancias, conocimientos y habilidades previas que hacen más proclive que ciertas ideas florezcan en determinados ámbitos. La o las preguntas en cuestión, y las acciones que se derivan de ellas, se gestan en un marco de relevancia que es histórico, social, político y que reconoce además acumulaciones individuales y colectivas. La investigación tiene lugar dentro de una comunidad científica, a la cual el investigador pertenece, y con la cual interactúa. Es este proceso dinámico el que determina la relevancia y la pertinencia de las preguntas y las respuestas. En nuestro caso, todos los miembros del equipo estamos ligados de un modo u otro a prácticas de intervención, extensión, gestión y/o militancia con jóvenes ${ }^{8}$. Esto nos aglutina, nos contiene y, a la vez, es fuente de preocupaciones y acumulaciones colectivas. Se confirma entonces que, en gran medida, los problemas de investigación no nacen de especulaciones meramente teóricas; en nuestro caso han surgido de prácticas interpeladoras. El contexto de surgimiento tiene larga data, la de la experiencia de todos y cada uno y la que compartimos como equipo. (Acevedo, 2017)

\footnotetext{
${ }^{8}$ Una característica del grupo de investigación es que todos sus miembros estamos y/o desarrollamos prácticas de intervención social, política cultural en organizaciones y grupos de jóvenes o espacios institucionales donde estos son los sujetos principales. En su mayoría, son jóvenes de sectores populares y los espacios a los que hacemos referencia son escuelas urbano-marginales, colectivos de jóvenes que luchan por sus derechos, murgas de barrios y/o villas, centros de estudiantes.
} 
De esta primera cuestión, la idea fuerza que quiero rescatar es que les investigadores somos seres situados, y desde esas biografías y en esos domicilios (que en ocasiones constituyen trincheras), conocemos y actuamos.

\section{RECUPERANDO VOCES Y EXPERIENCIAS JUVENILES EN PANDEMIA.}

LA NOCIÓN DE RUPTURA Y CRISIS EN LA VIDA COTIDIANA Y LOS

aportes de Orlando Fals Borda, Paulo Freire, Boaventura

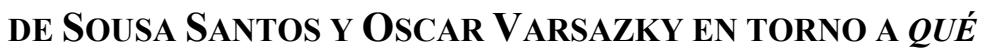

CONOCEMOS, CÓMO, CON QUIÉNES Y PARA QUÉ

La segunda idea que quiero recuperar tiene que ver con la noción de ruptura y crisis en la vida cotidiana, abordada también en la exposición La intervención social en contextos de pandemia, de mi colega Maria Inés Peralta cuando inauguraba los Diálogos desde el Trabajo Social ${ }^{9}$. Decía Maria Inés que las crisis y rupturas de certezas desde las cuales transitamos las incertidumbres del presente nos interpelan y arrojan un cúmulo de preguntas. Hoy estamos repreguntándonos por los cuidados entre les iguales y les diferentes; por la intervención del Estado y las políticas públicas (en educación, salud, trabajo); por los sujetos de la intervención y los modos de vivir, sobrevivir, enfrentar o no la crisis; por las redes y solidaridades que se activan o no; por la feroz y cruda evidencia de las desigualdades de todo tipo (desde el acceso al agua, alimentación, salud, educación, hasta la conectividad), por la protección social y estatal.

\footnotetext{
${ }^{9}$ Ibídem nota 2.
} 
Tantas veces — dictando clases — hemos afirmado ${ }^{10}$ que la vida cotidiana es aquello que transcurre de manera natural e incuestionable, aquello sobre lo cual no nos preguntamos, aquello que nos da una cierta tranquilidad porque es lo natural, es la vida misma. Agnes Heller (1994) explica que la vida cotidiana es el conjunto de actividades que caracterizan la reproducción de los sujetos particulares, los cuales, a su vez, crean la posibilidad de la reproducción social. En el concepto de vida cotidiana hay una primacía analítica de la temporalidad, ya que «la vida cotidiana implica la reiteración sistemática de acciones vitales, con una distribución del tiempo diaria» (Racedo, 2000: 180).

Entre las características de la vida cotidiana se encuentra el pragmatismo, la espontaneidad y la ultrageneralización. Por ello, en general, en la medida en que las respuestas con que nos movemos cotidianamente nos permiten continuar viviendo «normalmente», los procesos de ruptura y desnaturalización no son tan evidentes ni necesarios. Es así que podemos reiterar que — en general — cuando la vida cotidiana es puesta en crisis, se ve interrumpida e intervenida; cuando las certezas ya no sirven, cuando los ritmos y las explicaciones no nos son útiles, hay entonces lugar para la crisis y el cuestionamiento, para provocar o generar rupturas. Y quiero traer esta idea de irrupción porque desde hace meses nuestra vida cotidiana se vio modificada de manera abrupta por la pandemia; nuestras rutinas como sujetos en y desde las diversas posiciones que ocupamos se vieron movilizadas. Y fueron cambios no pautados ni planificados, sino que a la vez que fuimos produciendo otros modos de hacer las cosas (de «adaptarnos» por así decirlo) fuimos tratando de comprenderlos.

Podríamos afirmar que si hay algo de lo cual estamos seguros es de nuestra incertidumbre: no sabemos cómo evolucionará esta pandemia y qué consecuencias traerá a

\footnotetext{
${ }^{10}$ Hablo en plural en tanto, durante años, como docente de la asignatura Trabajo Social Comunitario — de la carrera Licenciatura en Trabajo Social (UNC) - he trabajado la noción de vida cotidiana, central para la comprensión de los procesos de reproducción de la vida de los sectores populares.
} 
nivel global, local, ni personal; no volveremos a lo conocido y reconocido; entonces, necesitamos comprender qué nos pasa para poder seguir viviendo en comunidad. Necesitamos contar con algunas (aunque fueran pocas) certezas, para actuar en la construcción de una nueva vida.

Como docentes universitarios, y como militantes sociales, educadores populares e investigadores, tenemos la responsabilidad social, política y teórica de preguntarnos qué estamos conociendo y para qué. $\mathrm{Y}$ digo responsabilidad social, porque no es solo responsabilidad de les individuos, sino de las instituciones.

La universidad es una institución pública y debe situarse en el contexto de crisis como tal e involucrarse en la comprensión de los problemas que nos acucian y en la búsqueda de respuestas y/o posibles soluciones. Entonces, no habría lugar a dudas en torno a la necesidad de un entendimiento y comprensión situada. Aun cuando el conocimiento social siempre se da en un contexto, tiempo y espacio determinado, hoy esta afirmación cobra otra fuerza, pues es ineludible situar y situarnos para poder comprender e intervenir. Tomo como referencias empíricas prácticas de investigación situadas que se desarrollaron en nuestra Facultad, y en particular, la experiencia del equipo de trabajo del cual formo parte y dirijo.

He seleccionado experiencias institucionales; solo enunciaré brevemente algunas de ellas, y me detendré en la experiencia particular del equipo de trabajo que dirijo (EntreGeneraciones, colectivo de investigación-acción con jóvenes).

Campaña Comer Bien «Con hambre no hay futuro»-Córdoba. En el mes de diciembre de 2019 se presentó el informe preliminar sobre el relevamiento de más de trescientos comedores y merenderos de Córdoba realizado por esta campaña. El mismo fue un trabajo colaborativo y colectivo desarrollado en conjunto con organizaciones de la sociedad civil cordobesa. El trabajo aportó al abordaje integral de la problemática del hambre 
y la malnutrición en la Argentina (en el marco de la Ley de Emergencia Alimentaria $N^{o}$ 27.345).

Este relevamiento constituyó y sentó bases sólidas (teóricas, empíricas y políticas) para el lanzamiento y sostenimiento de la Campaña Activemos Córdoba ${ }^{11}$ que, en el marco de la emergencia sanitaria y económica de nuestro país, llegó a quinientos centros comedores, merenderos y comedores/merenderos - de Córdoba Capital y el resto de la provincia; 530.000 platos de comida y 120.000 tazas de leche. Además, se difundió la situación de miles y miles de cordobeses atravesados por el hambre, las múltiples estrategias de sobrevivencia desarrolladas, se activaron redes intersectoriales y se generaron acciones multiactorales.

Relevamiento sobre la actuación de las fuerzas de seguridad en Córdoba. En el mes de abril de 2020 (apenas a un mes de decretado el ASPO $^{12}$ ), el Programa de Extensión «Seguridad y Derechos Humanos» de la Facultad de Ciencias Sociales (UNC) elaboró un Informe Preliminar con el objetivo de reseñar y sistematizar de manera provisoria los casos de violencia institucional por parte de las fuerzas de seguridad, en el marco de las detenciones y control establecidos para garantizar el aislamiento social y obligatorio por la emergencia sanitaria vinculada al Covid-19 en el Provincia de Córdoba. Este Informe y los acumulados de la Facultad en cuestión de derechos humanos constituyeron insumos centrales para el informe elaborado y presentado de manera conjunta con el CELS ${ }^{13}$ y distintas organizaciones

\footnotetext{
${ }^{11}$ \#ActivemosCórdoba (2020). Disponible en: https://sociales.unc.edu.ar/content/activemos-cordoba-solidaria

${ }^{12}$ El Aislamiento Social, Preventivo y Obligatorio es una medida excepcional que el Gobierno nacional adopta en un contexto crítico. Con el fin de proteger la salud pública frente a la propagación del nuevo coronavirus, se dispuso que todas las personas que habitan o se encuentren temporalmente en las jurisdicciones donde rige esta normativa, deberán permanecer en sus domicilios habituales, solo pudiendo realizar desplazamientos mínimos e indispensables para aprovisionarse de artículos de limpieza, medicamentos y alimentos.

${ }^{13}$ El Centro de Estudios Legales y Sociales es un organismo de derechos humanos argentino creado en 1979 - durante la última dictadura militar-, que promueve la protección de los derechos y su ejercicio efectivo, la justicia y la inclusión social a nivel nacional e internacional.
} 
sociales. El mismo fue elevado al gobierno provincial y aún circula por los diversos medios de comunicación local y nacional. Sentó posición en relación con la preocupación por los graves hechos de violencia institucional protagonizados por la Policía de Córdoba y se reclamó información sobre la adopción de medidas políticas e institucionales de fondo para controlar y profesionalizar esta fuerza policial, y al mismo tiempo, mejorar sus condiciones laborales.

Los efectos de la pandemia COVID-19: mucho más que un problema de salud. En mayo de 2020, a dos meses del ASPO, se presentó un informe que buscó relevar cómo impactan las medidas de aislamiento social en los cuerpos de mujeres, lesbianas y trans en Córdoba. La iniciativa fue impulsada por la Facultad de Ciencias Sociales de la UNC - a través del Programa Feminismo, Sexualidades y Derechos-y la Comisión Géneros y Disidencias del Consejo Social — conformada por CISCSA, Las Alicias Córdoba Capital, PS, SeAP y Católicas por el Derecho a Decidir- La consulta tuvo como objetivo indagar sobre los efectos de las medidas de aislamiento social preventivo y obligatorio sobre la situación económica y laboral, preocupaciones, tareas de cuidado, anticoncepción y violencias de género. También se propuso contar con información que oriente demandas y propuestas para las autoridades locales. Se elaboró un informe de circulación masiva, se difundió y trabajó en diversos espacios públicos (societales y estatales).

Jóvenes cordobeses: ¿les olvidades en la cuarentena? La pandemia y las políticas sanitarias de aislamiento social pusieron al desnudo desigualdades profundas y preexistentes en nuestro país y en el mundo entero. Y aunque el ASPO ha mostrado ser casi la única herramienta efectiva de prevención, muchos de sus impactos en ciertos grupos sociales debieran ser una señal sobre las intervenciones estatales que faltaron (sobre todo en nuestra provincia) y las que deberían pensarse para la salida de la cuarentena. Las principales dificultades que enfrentaron les jóvenes fueron las carencias y esfuerzos para sostener 
actividades escolares, la pérdida del trabajo, la ausencia de espacios de socialización propios y transitar incertidumbres y preocupaciones nuevas.

Muchas de las noticias y comentarios que circulan sobre jóvenes tienen una matriz adultocéntrica. Son nombrados en las voces de docentes que se quejan, de padres y madres que sienten la sobrecarga de acompañarles en actividades escolares y que muchas veces no encuentran modos de ayudarles en tránsitos emocionales difíciles. En otras ocasiones, les jóvenes son puestos en noticias vinculadas a violencia machista o abuso policial por supuesta violación de la cuarentena; en los últimos tiempos, la mayoría de las noticias ligadas al aumento de casos y propagación del virus señalan a les jóvenes como «los culpables».

¿Quiénes se preguntan cómo están pasando la cuarentena las jóvenes? ¿Cómo ha impactado en sus vidas? ¿Qué problemas suscita para las jóvenes las medidas de aislamiento social? ¿Qué estrategias construyen para sortear las dificultades? Estas fueron y son algunas de las preocupaciones de un equipo que desde hace más de diez años investigamos, trabajamos, militamos, hacemos docencia de grado y posgrado en torno a les jóvenes. Nuestros productos ${ }^{14}$ son fruto del trabajo colectivo que un conjunto heterogéneo de investigadores desarrollamos entre mayo y agosto de 2020. Somos investigadores del IPSIS (Instituto de Política, Sociedad e Intervención Social de la Facultad de Ciencias Sociales de la UNC).

Decía que es fruto del trabajo colectivo y también es un producto artesanal, por cuanto un conjunto de investigadores formados trabajamos codo a codo junto a jóvenes que a partir de esta investigación se iniciaban en el oficio de investigar. A modo de un taller en que artesanos y aprendices construyen piezas únicas, el proceso desarrollado durante el corriente

\footnotetext{
${ }^{14}$ Más sobre el equipo de investigación en https://juventudes.sociales.unc.edu.ar/quienes-somos/
} 
año y los productos que de él se derivan, constituyen una pieza de orfebrería cultivada con cariño y experticia.

El rediseño, la revisión del foco. ¿Qué impacto tuvo el contexto de aislamiento social en las condiciones de vida de les jóvenes? En el marco del rediseño de un proyecto de investigación ${ }^{15}$, aprobado y financiado por un lapso de cuatro años, y atendiendo al contexto de ASPO, trabajamos con un estudio descriptivo buscando respuestas a la siguiente pregunta: ¿qué impacto tuvo el contexto de aislamiento social en las condiciones de vida de les jóvenes? Nuestro estudio combinó la recolección de encuestas autoadministradas con la construcción de crónicas. En la dimensión cuantitativa, indagamos sobre las actuales condiciones de vida de les jóvenes cordobeses, principalmente sobre las situaciones laborales, educativas y familiares. Realizamos el estudio a través de una muestra de la población juvenil entre 14 y 22 años que reside en la ciudad de Córdoba y Gran Córdoba. La encuesta fue realizada en el mes de mayo a través de la aplicación de un formulario en línea autoadministrado, abarcando a casi seiscientos jóvenes cordobeses. Esto fue posible y relativamente sencillo, dada la experiencia de trabajo y la cercanía generacional (en el caso de los estudiantes miembros del equipo) con los jóvenes entrevistados.

Dados los objetivos, intereses y trayectoria del equipo, nos interesaba recuperar las particularidades de la vida cotidiana de los jóvenes en contexto de pandemia, por lo que nos propusimos hacer el ejercicio de registrar y sistematizar sus prácticas, vivencias y emociones. Invitamos a noveles investigadores miembros del equipo a producir crónicas, reconociendo un modo de escritura que permite relatar acontecimientos significativos, lo que para Reguillo (2000) son «relatos que aspiran a consignar la vida en la contradictoria complejidad de su simpleza». Poder visibilizar, dar voz y presencia a vivencias de jóvenes, recuperar emociones, ansiedades, miedos, alegrías, ideas, apuestas y estrategias, en el marco de

\footnotetext{
15 «Jóvenes, educación, trabajo y participación: Estrategias y circuitos de acceso que los jóvenes de sectores populares despliegan en contextos y tiempos de restricciones». Proyecto Consolidar 2018-2021-SECYT UNC.
} 
diversos aspectos que restringen y/o posibilitan el acceso a derechos, fue el desafío en la producción de las crónicas. Los acontecimientos de jóvenes a referenciar están doblemente atravesados: por un lado, las disposiciones sociales, políticas, culturales, económicas propias en lo generacional; por otro, las vivencias —y agudización — de esas disposiciones en el marco de la pandemia y medidas de aislamiento social de emergencia. Las crónicas se presentaron como un dispositivo que nos permitió, en decir de Reguillo, graficar el «permanente tránsito de historias y de memorias, que siendo mapas individuales configuran un mapa colectivo», enfocando la atención — narración mediante - en cuestiones de lo cotidiano que muchas veces no son contadas. Fueron producidas por noveles investigadores y acompañadas por docentes miembros del equipo. Durante la cuarentena, cada integrante a modo de artesano y aprendiz - fuimos trabajando las crónicas, indicando, preguntando, acompañando y alentando la escritura. Generamos encuentros con les estudiantes para proponer criterios, realizamos devoluciones colectivas e individuales, señalamos e identificamos particularidades y tendencias. Cada joven-ayudante de investigación seleccionó a otro con quien trabajar, una hermana, amigue, conocido, compañeros de estudio o trabajo. La primera sesión de trabajo colectivo fue poner en común y justificar los criterios de selección tenidos en cuenta. En todos los casos, la cercanía generacional, el contacto previo, el escuchar historias o comentarios, y la predisposición de quien «hablaba» fueron primacía. Las crónicas, antes narraciones, se recogieron de diversos modos mediados por la virtualidad, en general por Whatsapp, videollamadas, Meet, Zoom, entre otros.

Todo el proceso de investigación se desarrolló en y desde la virtualidad, es así que nuestro taller de artesanía intelectual ${ }^{16}$ fue mediado por una pantalla de celular o computadora e interrumpido por cortes de luz, mala o nula conectividad. Sin embargo, a lo

\footnotetext{
${ }^{16}$ La idea de artesanía intelectual la tomamos de C. Wright Mills (1997).
} 
largo de dos meses intensos de trabajo con una frecuencia semanal, además de recoger seiscientas encuestas (y procesar y analizar sus resultados), producimos catorce crónicas.

\subsection{Algunos Resultados}

Los resultados que transcribo son, en gran parte, textuales del informe original que produjo el equipo y del cual se derivaron un sinnúmero de productos ${ }^{17}$. Asimismo, he seleccionado algunos tópicos que considero relevantes, ya que no es motivo de este artículo explayarme en el conjunto de los resultados. Los que expongo son aquellos que de modo reiterado han constituido (aún constituyen) tópicos motivo de diálogos, críticas, comentarios, opiniones tanto desde las ciencias sociales como desde el sentido común en torno a qué piensan, hacen, cómo se comportan les JóVENES en pandemia.

¿Quiénes son? El promedio de edad de quienes respondieron las encuestas fue de 18 años y en relación con el género de la población encuestada, el $65 \%$ lo conformaron mujeres, el 34\% varones y el 1\% otros géneros. En cuanto a las características sociohabitacionales, el $50,5 \%$ pertenece a barrios considerados de sectores medios, el $33,2 \%$ a barrios populares y el 16,3\% a barrios de sectores altos. La gran mayoría de les jóvenes (el 86,8\%) está pasando el período de cuarentena con su familia nuclear (padres, madres y hermanes), un 9,1\% con familia extendida (familia nuclear más otros familiares). Solo un $0,7 \%$ lo está pasando sole.

\footnotetext{
${ }^{17}$ Jóvenes en cuarentena: una investigación situada-IPSIS (Instituto de Políticas, Sociedad e Intervención Social), Facultad de Ciencias Sociales. Equipo de investigación: directora, magíster Patricia Acevedo; codirectora, licenciada Susana Andrada; miembrxs docentes: licenciada Paola Machinandiarena, licenciado Luis Arévalo, magíster Eliana López, licenciada Valentina Tomasini, licenciado Nicolás Giménez; egresadxs: licenciada Consuelo González Clariá; ayudantes estudiantiles: Marco Villa, María Guillermina Ulloa, Zahira Toledo, Josemir Gómez, Antonella González, Serafín Moreno, Rocío Müller, Lucía Nannini, Nayla Luz Sabattini, María Belén, Pablo Salinas, Micaela Beltrán.
} 


\section{2 ¿LA ESCUELA SE VUELVE MÁS LEJANA?}

El estudio muestra que ocho de cada diez jóvenes está cursando algún nivel educativo (secundario o educación superior), y sin dudas es un indicador de la efectividad de la obligatoriedad de la educación secundaria, y de la universalidad de la política pública. Sin embargo, esto no da cuenta de las diferencias entre propuestas educativas, las condiciones en las que se desenvuelve la escolaridad y el modo en que los puntos de partida de les jóvenes impacta en el aprendizaje. Y son estas desigualdades las que se profundizan con la virtualización de la escolaridad.

La disponibilidad de recursos tecnológicos y el acceso a conectividad en tiempos donde el grueso de las actividades sociales se trasladó a la modalidad remota, constituye un punto crucial para pensar en el acceso a derechos.

En cuanto al equipamiento tecnológico en sus viviendas, el 75,9\% cuenta con TV, el $41 \%$ con teléfono fijo y el $90,5 \%$ con acceso a internet por wi-fi, mientras que un $2,9 \%$ no cuenta con ninguna de estas posibilidades de conectividad. En relación con los dispositivos en el hogar para desenvolverse durante la cuarentena, el 58,9\% posee notebook, el $42 \%$ cuenta con PC de escritorio y el 11,5\% posee una netbook de programa Conectar Igualdad, lo que demuestra un contraste entre aquelles que tienen más de un dispositivo electrónico en su vivienda y quienes no tienen ningún dispositivo de este tipo.

Pero no se trata únicamente de que el dispositivo exista en el hogar, sino también de la calidad del mismo, de las posibilidades de les jóvenes de acceder a su uso, de la cantidad de dispositivos relacionado con la cantidad de personas que lo necesitan, de cómo pueden o no adaptarse los espacios habitacionales a las necesidades educativas, entre otras innumerables situaciones específicas donde se entretejen las desigualdades de esta coyuntura. Quizás parte de esto se refleje en que casi la mitad de les jóvenes tienen dificultades de diferentes grados en el cursado (un 35,6\% afirma estar cursando pero con alguna dificultad, 
el 7,6\% expresa estar cursando con muchas dificultades y un 6,2\% directamente no está pudiendo cursar).

Sin dudas hay un grupo en condiciones muy desfavorables para hacer frente a la escolaridad virtual y esto se vincula, entre otras cuestiones, con los recursos tecnológicos. El $12 \%$ de elles debe realizar sus tareas desde un celular — propio o de un familiar-, por no contar con un computador disponible para esa actividad; de ese grupo, el $23 \%$ pertenece a sectores medios y el 44,6\% a sectores populares. Un $6 \%$ de les encuestades no cuenta tampoco con celular ni propio ni compartido y debe pedir prestado en última instancia. Del $10 \%$ del total de encuestades que no tienen acceso a internet, un $75 \%$ corresponde a los sectores populares y un $25 \%$ a los de sectores medios. Por lo tanto, realizar tareas implicó una inversión monetaria extra para las familias en algunos casos.

La accesibilidad a la conectividad es uno (pero no el único) de los principales indicadores para mirar la calidad en la permanencia e inclusión educativa de les jóvenes en este excepcional contexto. Creemos que las brechas tecnológicas, pero también culturales y educativas, adquieren mayor relevancia en un contexto donde la accesibilidad pasa específicamente por la disponibilidad de saberes para desenvolverse en entornos virtuales. Y allí los capitales culturales y sociales de las familias adquieren más relevancia para que las exigencias escolares puedan resolverse con éxito.

\subsection{EL TRABAJO JUVENIL EN TIEMPOS DE CUARENTENA: LES EXCLUIDES DEL TELETRABAJO}

Les jóvenes son un grupo particularmente afectado por el desempleo, la precariedad e inestabilidad laboral. Antes de la cuarentena, un 19,7\% en el total de la población consultada estaba desempleada, afectando más a las mujeres (de ese grupo son un 72\%) y les

jóvenes en peores condiciones socioeconómicas (el 46\% pertenece a los sectores populares, 
el $43 \%$ a sectores medios y un $11 \%$ a los sectores altos). Del total de jóvenes encuestades, aquellos que trabajan, solo el $4 \%$ lo hace de manera registrada y un $27 \%$ en situación de informalidad.

Ante la pregunta «¿qué sucedió con tu trabajo una vez iniciada la cuarentena?», de les que se encontraban trabajando (son el 35\% de les encuestades), el 64,2\% afirma que no pudo continuar trabajando y que no está percibiendo los mismos ingresos que antes, lo cual muestra que constituyen un sector especialmente vulnerable. Solo un $8 \%$ de les jóvenes que trabajan manifestó que ha continuado realizando su actividad laboral, adecuándose a la modalidad del trabajo «en casa» o teletrabajo. La idea homeoffice, teletrabajo u otras variantes, como términos que adquirieron relevancia en este contexto, no aplican de manera significativa en la realidad laboral de les jóvenes, siendo en todo caso conceptos exclusivos para caracterizar el trabajo adulto, asalariado y formal, pero no juvenil.

Esto es de mayor gravedad si se tiene en cuenta que en Córdoba quedaron sin efecto programas de inclusión laboral orientados específicamente a jóvenes (PPP y PIT) junto con otros orientados a otros sectores sociales (Pila a varones adultos y X Mí a mujeres adultas).

\subsection{VIDA COTIDIANA: ACTIVIDADES, PREOCUPACIONES Y EMOCIONES}

Sobre las principales actividades cotidianas de les jóvenes durante la cuarentena, la de mayor peso es la «realización de tareas escolares» (el 78\% de les encuestades) y por debajo se ubican «ver redes sociales» con un 58,7\%, y 58,5\% «ver videos y películas». Sin duda, mucha pantalla en los tiempos cotidianos, lo que probablemente tendrá su impacto en la salud y exigirá abordajes específicos. La realidad cotidiana de les jóvenes (al igual que la mayoría) muestra cómo sus relaciones con otres dejaron de ser cara a cara para trasladarse «pantalla a pantalla», y cómo la virtualidad ha cobrado un peso significativo en su cotidianidad. 
Con relación a qué actividades disfrutan dentro de las acotadas posibilidades del «encierro», expresaron en un $58,9 \%$ ver películas, un $54,1 \%$ estar con la familia y un $40 \%$ hablar con amigues, principalmente a través de las redes sociales.

La gran mayoría $(74,2 \%)$ antes de la cuarentena tenía actividades no ligadas a lo escolar; de ese grupo, el 35\% realizaba algún deporte, el 19,4\% participaba de un grupo juvenil, el 19,7\% acudía a un taller artístico y/o cultural, el 5\% estaba realizando algún curso de oficio, entre otras. La mitad no pudo seguir con estas actividades debido a la cuarentena. Esto es especialmente significativo si tenemos en cuenta el lugar que tienen en la sociabilidad juvenil el encuentro, las amistades, la recreación y la participación. La iniciativa estatal en relación con estas necesidades estuvo ausente; en Córdoba los Centros de Actividades Juveniles «cerraron», no sostuvieron ninguna modalidad virtual de trabajo y sus trabajadores desconocen si habrá continuidad. Por lo que el acceso se circunscribe al mercado, a poder pagar un gimnasio, la escuela de fútbol, talleres de oficios u otros que ofrecieran actividades virtuales.

Al consultar sobre las preocupaciones y emociones de les jóvenes, nos encontramos con que los estados de ánimo predominantes son el aburrimiento (un 61,7\%), el cansancio $(53,6 \%)$ y, por último, la ansiedad (43,3\%). Las emociones son comprensibles en el contexto de la cotidianeidad: el peso que tienen las actividades escolares en las rutinas, la suspensión de actividades recreativas y/o esparcimiento y la pérdida de espacios de socialización.

Las mujeres jóvenes se reconocen más cansadas, aburridas y ansiosas que los varones, y esta diferencia se debe principalmente a la división de género y a las tareas domésticas que se producen al interior de la familia, mayormente como responsabilidades asumidas por las mujeres del hogar, y en les jóvenes, esta situación no es la excepción. Contrariamente a ello, en las emociones «positivas», quienes aparecen más representados son los varones. Por ejemplo, entre quienes se sienten «contentes» se identifican el $24,4 \%$ de varones, en 
contraposición al 16,3\% de las mujeres, y en la emoción «tranquiles» se ubica un 42,8\% y $28,2 \%$ de hombres y mujeres, respectivamente. También influyen en esta diferencia las construcciones de género; las mujeres han aprendido a expresar emociones, atenderlas, vivirlas como parte fundamental de lo femenino, a diferencia de los varones, cuya emocionalidad es reprimida, más si se trata de emociones que socialmente se representan como «debilidad».

\section{5 ¿OLVIDADXS?}

Si bien les jóvenes aparecen de modo predominante en las preocupaciones de la política educativa, son puestes en el lugar de receptores de las acciones adultas. En Córdoba, en particular, sufrieron el recorte de programas específicos. En un momento cuando se necesitaba de mayor presencia estatal desde la seguridad social, el Estado hizo un paso al costado. A nivel nacional, les jóvenes fueron un grupo beneficiado en un $20 \%$ por la IFE; sin embargo, esto no fue el fruto de los objetivos de la política hacia el grupo social, sino de la precariedad de su condición social.

Les jóvenes son nombrades en las voces de docentes que se quejan de que no entregan tareas, en las voces de padres y madres que sienten la sobrecarga de acompañarles en actividades escolares, no encuentran modos de ayudarles en tránsitos emocionales difíciles; o son puestos en lo público en alguna noticia cuando son víctimas de la violencia machista, o del abuso policial porque supuestamente violaron la cuarentena.

Sin duda, les jóvenes deben ser reconocides también como actores sociales fundamentales de este tiempo; han desplegado estrategias individuales y colectivas para enfrentar los desafíos de la cuarentena, y esto y sus situaciones de vida han estado invisibilizadas, lo que nos obliga a proponer una mirada generacional en torno al contexto actual. La participación, sus voces y propuestas deben estar presentes en aquello que se 
piense como salida de la cuarentena, tanto en la escuela, en el trabajo, la salud y las acciones comunitarias barriales.

De esta Investigación se derivaron varios $\operatorname{productos}^{18}$ : nuestro aporte al sitio Elaboraciones de la Facultad de Ciencias Sociales, un corto que recupera voces de las crónicas y articula con datos de la encuesta: Jóvenes en pandemia y un Informe de divulgación masiva Jóvenes en pandemia. Todos y cada uno de ellos han circulado - y continúan circulando - entre docentes, jóvenes, funcionarios y equipos técnicos de salud, educación y otros espacios de atención juvenil. Diversos medios de comunicación recogieron los resultados y difundieron los mismos.

Las experiencias descritas, a mi criterio, forman parte de legados epistemológicos, teóricos y políticos de algunos autores que, como he dicho, me han influenciado y hacen parte de la investigadora, docentes y educadora popular que hoy soy. Me refiero y traigo entre ellos a Orlando Fals Borda — sociólogo colombiano-, quien influenció a generaciones de sociólogos, cientistas populares, militantes sociales y políticos de su país y de toda América Latina, por medio de su prolífica producción académica y militancia y coherencia académico-política. De Fals Borda, entre otros, heredamos los postulados de la Investigación-acción-participativa.

Paulo Freire, educador brasilero, padre de la educación popular, quien fuera uno de los mayores y más significativos pedagogos del siglo XX, con su principio del diálogo nos mostró un nuevo camino para la relación entre profesores y estudiantes. Fue el pedagogo de los oprimidos y en sus trabajos transmitió la pedagogía de la esperanza. Influyó en las nuevas ideas liberadoras en América Latina y en la teología de la liberación, en las renovaciones

18 Para ver en línea: Portal web (shorturl.at/knoEQ), Corto animado (shorturl.at/fgCM1) e Informe (shorturl.at/cqyP0). 
pedagógicas europeas y africanas, y su figura es referente constante en la política liberadora y en la educación.

Boaventura de Sousa Santos es doctor en Sociología del Derecho por la Universidad de Yale, profesor catedrático de Sociología en la Universidad de Coimbra y director del Centro de Estudios Sociales de esa misma universidad, considerado uno de los principales intelectuales en el área de ciencias sociales, en particular por sus aportes para pensar temas como la epistemología, la globalización, la democracia y los derechos humanos.

Y, por último, Oscar Varsavsky, quizás el menos conocido por quienes circulamos por las ciencias sociales, quien nació en Buenos Aires en 1920 y cursó sus estudios universitarios en la Universidad de Buenos Aires, donde obtuvo el grado de doctor en Química de la Facultad de Ciencias Exactas. Realizó una fuerte crítica a las normas que rigen el desarrollo de las ciencias. Opinaba que la obsesión por los métodos cuantitativos encubre, en la ilusión de la libertad de la investigación, un mecanismo que garantiza la sujeción del científico a las estrategias de expansión del capital y las leyes del mercado. Estas ideas fueron su punto de partida para aspirar a una ciencia más libre de los condicionamientos de los poderes.

De los dos primeros, retomo la ruptura con el paradigma de ciencia natural-positiva: sus críticas a la objetividad y neutralidad de las ciencias, la distancia entre sujeto-objeto y la cuestión de quién conoce y cómo. Nuestra experiencia de investigación Jóvenes en pandemia ha consistido en un proceso de colaboración, ya que parte del equipo son y se reconocen jóvenes. Elles no solo han participado activamente en la construcción de los instrumentos, sino que sus innumerables contactos nos permitieron llegar en una semana a más de seiscientos jóvenes que respondieron las encuestas y en un mes realizaron las crónicas. Las voces juveniles fueron rescatadas y amplificadas por les mismes jóvenes. Fals Borda (desde la sociología) y Paulo Freire (desde la pedagogía) desarrollan el postulado clásico acerca de 
que todos conocemos y todos aprendemos. Y no bastarían las páginas de un artículo para dar cuenta de los inmensos aprendizajes intergeneracionales que nos ha producido esta experiencia que venimos desarrollando.

Por su parte, Boaventura es un autor que a fuerza de persistencia de algunos docentes, y sin dudas de su enorme potencial, humildad y capacidad para comunicar y provocar, circula y está legitimado en algunas universidades. También por su impecable coherencia entre ideas y prácticas, y sus aportes para ayudarnos a pensar con relación al agotamiento intelectual y político del Norte global e invitarnos a producir conocimiento desde el Sur. Para Boaventura, el Sur es una metáfora del sufrimiento humano causado por las grandes formas de opresión - el capitalismo, el colonialismo y el patriarcado - y las varias formas de lucha y resistencia a esas formas de opresión. En este sentido, su propuesta de las Epistemologías del Sur intenta ampliar las posibilidades de repensar el mundo a partir de saberes y prácticas del Sur Global, desafiando los intentos de epistemicidio o subalternización epistémica. Solo citar (del inmenso caudal de enseñanzas) la idea de hacer visible lo invisible, nuestra investigación ha tenido múltiples repercusiones, notas e informes en diversos medios de comunicación, académicos, sociales, educativos. Les jóvenes investigadores del equipo pusieron en público sus/las voces juveniles. Ante la avalancha (casi desmedida) de explicaciones desde el prejuicio, la opinión y la locura ágil con relación a que les jóvenes eran, casi como únicos responsables, quienes llevaban el virus del Covid-19 de un sitio a otro, pocas voces (aun las mejor intencionadas políticamente) contaban con relevamientos, información y voces juveniles que expusieran y se expusieran de otro modo. Retomo a Boaventura, y me atrevo a hipotetizar e incluir esta experiencia no solo en el marco de la educación popular y la investigación situada, sino como un ejercicio de sociología de las ausencias (afirmación que me propongo y estoy desarrollando en otro artículo, ya que supone mayores precisiones). Dice Boaventura: «La Sociología de las ausencias es un procedimiento transgresivo, una sociología insurgente para intentar mostrar que lo que no existe es producido activamente 
como no existente, como una alternativa no creíble, descartable, invisible a la realidad hegemónica del mundo» (Boaventura, 2006: 23).

\section{NO TODA INVESTIGACIÓN SOCIAL ES INVESTIGACIÓN SITUADA. LA INVESTIGACIÓN SITUADA COMO MODO DE INTERVENCIÓN SOCIAL}

En el presente apartado y de manera arbitraria, expongo algunas características de las experiencias señaladas que me permiten considerarlas como investigación situada y que operan a modo de conclusiones.

En todos los casos son investigaciones situadas en tiempo y espacio cercano. No existe la posibilidad de conocer desde ninguna parte, siempre lo hacemos desde un cuerpo, una historia, un tiempo y un lugar. Situar es ubicar el tiempo y el espacio en que se produce el conocimiento y quien/es lo producen/producimos. Situarse es comprender el lugar que ocupo, mi posición frente a la del otro y la posición del otro frente a mí, y dialogar, reconocer conocimientos, saberes y reconocer sujetos que lo producen. En particular y como he descrito de modo precedente, el equipo de investigación en juventudes está conformado por docentes, graduades y estudiantes con inserción territorial y/o institucional y trabajo con jóvenes. Algunos han sido y/o son dirigentes estudiantiles, otres profesionales de larga trayectoria en el campo de la salud y el trabajo; estamos quienes por nuestra edad combinamos varias de estas características, la/s preocupaciones por las juventudes nos constituyen, somos nosotres el equipo y a la vez varies son otres, elles, les jóvenes .

En todos los casos, las investigaciones citadas y en particular la desarrollada en torno a les jóvenes son promovidas por equipos de investigación y trabajo que tienen larga data en las temáticas que abordan. Que sea situada, que se concrete en pocos meses, no significa que no haya teoría, que no exista experiencia, que no haya prácticas previas, que sea pura acción, 
que se reduzca a tomar encuestas o a realizar relevamientos. Cada uno de los informes producidos contiene referencias empíricas que lo sustentan.

En el caso del proceso desarrollado con les jóvenes, recogimos seiscientas encuestas en una semana. Ello fue posible porque contamos con un acumulado teórico y empírico en relación con las juventudes, hemos producido y aplicado instrumentos similares en otros estudios, tenemos experticia y sabemos cuántos ítems e interrogantes (aproximadamente) pueden indagarse en y con un instrumento de este tipo. En el equipo, y en una ágil división de tareas, algunes confeccionamos el instrumento que fue probado con y entre más de quince jóvenes, y otres trabajamos el tema de las crónicas, capacitamos a les estudiantes, orientamos y acompañamos. Los procesos no son fruto de la improvisación ni el desconocimiento; hay conocimiento previo y experticia metodológica. Pero, sin dudas, hay voluntad política de involucrar investigación y acción.

En todos los casos, son investigaciones realizadas con otres (no con otros individuales, sino con otros colectivos), y sus palabras cuentan y valen no solo como insumo, sino como saberes para la comprensión. Son mujeres de los barrios con los que se trabaja desde hace años, son jóvenes y trabajadores de la salud y la educación con jóvenes, son las víctimas de la violencia policial, son vecinos de barrios populares, quienes no solo brindan sus palabras, sino quienes colaboran en la confección de los instrumentos, en la recolección de la información, en la circulación y el uso de los resultados.

En todos los casos, la intervención es información que ha sido recogida $y$ conocimiento que es producido para incidir en las políticas públicas, en los efectores y/o trabajadores de salud, educación y trabajo, y poseen perspectiva de género. Es información que permite confirmar o redefinir el curso de las acciones e intervenciones políticas y sociales, que tiene la pretensión de modificar representaciones sobre los sujetos y en los sujetos. 
Me atrevo a decir que estas investigaciones encarnan la idea de artesanía intelectual de Wrigth Millsy de apertura de las Ciencias Sociales de Wallerstein: no son propiedad de una disciplina, no son recetas, no son copias, no son mera metodología; pero tampoco son acciones al azar, ni que no tengan lógica ni rigurosidad. Poseen e incorporan otras/diversas lógicas y recurren a otros modos de recoger información. Construimos crónicas a partir de Whatsapp o charlas telefónicas e interactuamos con la información de al menos tres sujetos: les jóvenes que narraban, quienes recogían la información y la sistematizaban, y les docentes que orientábamos.

En todos los casos hay teoría, antecedentes, experiencia acumulada, rigurosidad metodológica y rescate de palabras y experiencias; hay otros que son sujetos que coproducen conocimiento. Hay, también, sentido de la urgencia y responsabilidad social en producir conocimiento, en comprender, describir y explicar para intervenir, modificar e incidir. Podemos decir que la intervención social es un concepto que abarca el conjunto de procesos y estrategias que tienen lugar en la implementación-gestión de políticas sociales y en las múltiples formas de acción colectiva que desarrollan los sujetos en torno al acceso a derechos.

Situarse no es mimetizarse con el diferente. Situarse es, siendo consciente de mi identidad, comprender a otros individuos, sus ideales e intereses. He partido diciendo que la investigación situada es un modo de intervención. Y considero ello en la medida en que los sujetos con los que trabajamos coproducen y acceden a otro conocimiento sobre su situación, modifican sus representaciones sobre sí mismos, cuentan con mayores herramientas para la transformación, la organización y la lucha por mejores condiciones de vida. Además, puede constituir una herramienta para las disputas políticas.

Así como un respirador puede salvar vidas, conocer los efectos del encierro en mujeres que viven en hogares violentos podría reducir los casos violencia doméstica. Recoger y hacer circular las voces de jóvenes en pandemia es un modo de construirlos en 
protagonistas, permitirles reflexionar y elevar su autoestima. Quienes impugnan prácticas juveniles podrían revisar sus prácticas prejuiciosas y estigmatizantes.

La investigación situada produce conocimiento en y con involucramiento de los sectores populares para propiciar prácticas emancipadoras. Nos propusimos generar metodologías desde una mirada dialógica, participativa, colaborativa y multidimensional. Y también, recuperar la significancia teórica y metodológica del concepto de Vida Cotidiana como espacio de construcción de saberes, de intervención y transformación social.

Boaventura de Sousa Santos (2006: 37) afirma: «Ya no se trata sólo de conocer la realidad sino de preguntarse ¿qué conocimiento, para qué mundo?», y su pregunta invita a repensar:

- Los objetos/problemas/temas que construimos como objetos de conocimiento;

- Los modos en que producimos conocimiento;

- Los sujetos con quienes investigamos y la participación en la producción del conocimiento;

- Las teorías y metodologías que usamos;

- Los modos en que hacemos circular el conocimiento.

En este artículo he intentado describir y fundamentar experiencias de investigación situada desde la Universidad Pública. Son y han sido posibles desde una Facultad de Ciencias Sociales recientemente creada, que recoge los mejores legados y prácticas que diversas generaciones de universitaries dejaron y siguen marcando huellas.

Como se deriva de nuestro estudio (y otros tantos) y como lo manifiestan les jóvenes, las estrategias en la pandemia — en general — han sido adultocentristas, centradas en el control y el desconocimiento de les jóvenes como grupo específico. Ante esta constatación, al cierre de este envío, la retroalimentación continúa y nos encontramos en la etapa de 
producción de cortos audiovisuales y otras estrategias comunicacionales, todos elaborados en y con jóvenes estudiantes para desarrollar una campaña de cuidado con relación al Covid19. La propuesta es continuar con una línea de conocimiento y acción desde y hacia les jóvenes; estamos produciendo, de manera colectiva, mensajes que partan de su reconocimiento y estén formulados con una perspectiva generacional que les tome en cuenta y trabaje con y para elles.

RECIBIDO: 24 DE MARZO DE 2021

ACEPTADO: 17 DE MAYO DE 2021

\section{BibLIOGRAFÍA}

ACEVEDO, M. P. (2017). Reconstrucción y relación entre investigación e intervención con jóvenes. IDES-Prácticas de Oficio, 2(18). Disponible en: ides.org.ar/publicaciones/practicasdeoficio

BACHElard, G. (1972). La formación del espíritu científico. México, D.F.: Siglo XXI.

Barcelo Racedo, J. (2000). Crítica de la vida cotidiana en comunidades campesinas. Buenos Aires: Cinco.

BEKER, H. (2011). Manual de escritura para cientificos sociales. Cómo empezar y terminar una tesis, un libro o un artículo. Buenos Aires: Siglo XXI.

Blazquez Graf, N., Flores Palacios, F. y Ríos Everardo, M. (coords.) (2010). Investigación feminista: epistemología, metodología y representaciones sociales. México, D.F.: Centro de Investigaciones Interdisciplinarias en Ciencias y Humanidades Universidad Nacional Autónoma de México/Centro Regional de Investigaciones Multidisciplinarias/Facultad de Psicología, 2012 (Colección Debate y Reflexión).

Bourdieu, P. (1993). La miseria del mundo. Buenos Aires: Fondo de Cultura Económica.

Bourdieu, P., Chamboredon, J. C. y Passeron, J. C. (1975). El oficio de sociólogo. Buenos Aires: Siglo XXI.

De Sousa SAntos, B. (2006). Renovar la teoría crítica y reinventar la emancipación social. Buenos Aires: CLACSO.

GARcía SALORD, S. (comp.). (2000). ¿Cómo llegué a ser quién soy? Una exploración sobre historias de vida. Córdoba: Ediciones del CEA-Universidad Nacional de Córdoba. 
GUBER, R. (1984). El salvaje metropolitano. Buenos Aires: Legasa.

HABER, A. (2011). Nometodología payanesa: Notas de metodología indisciplinada. Revista Chilena de Antropología, (23). doi:10.5354/0719-1472.2011.15564

HARDING, S. (1996). Ciencia y feminismo. Madrid: Morata.

Heller, A. (1994). Sociología de la Vida Cotidiana. Península.

INSTITUTO OSCAR VARSAVSKY (2019). Fundamentos teórico-políticos. Una apuesta para revitalizar el debate público acerca de la política científica y académica en nuestra región. Córdoba.

Mannheim, K. (1928). El problema de las generaciones. Revista Española de Investigaciones Sociológicas, 62, 193-242 [1993].

Piovani, J. (2018). ¿Condenados a la reflexividad? Buenos Aires: Biblos/CLACSO.

RACEDO, J. (2000). Crítica de la vida cotidiana en comunidades campesinas. Buenos Aires: Cinco.

Reguillo, R. (2000). Textos fronterizos. La crónica, una escritura a la intemperie. Revista Diálogos de la Comunicación, 58-65.

RoBerTI, E. (2019). Las trayectorias educativo laborales como herramienta teóricometodológica. En Curso Virtual: La formación para el trabajo de jóvenes. Herramientas teóricas metodológicas, Clase 9, PREJET, Ides-CIS-Conicet.

WAINERMAN, C. y SAUTU, R. (1997). La trastienda de la investigación. Buenos Aires: Editorial de Belgrano.

WALlerstein, I. (coord.). (1996). Abrir las ciencias sociales. México, D.F.: Siglo XXI.

Wright MiLl, Ch. (1997). Sobre artesanía intelectual. En La imaginación sociológica. México, D.F: Fondo de Cultura Económica. 